\title{
Cerebellar Growth Impairment Characterizes School-Aged Children Born Preterm without Perinatal Brain Lesions
}

\author{
(D) K. Pieterman, (D)T.J. White, (D) G.E. van den Bosch, (D)W.J. Niessen, (D).K.M. Reiss, (DD. Tibboel, (D)F.E. Hoebeek, and (D). Dudink
}

\begin{abstract}
BACKGROUND AND PURPOSE: Infants born preterm are commonly diagnosed with structural brain lesions known to affect long-term neurodevelopment negatively. Yet, the effects of preterm birth on brain development in the absence of intracranial lesions remain to be studied in detail. In this study, we aim to quantify long term consequences of preterm birth on brain development in this specific group.
\end{abstract}

MATERIALS AND METHODS: Neonatal cranial sonography and follow-up TI-weighted MR imaging and DTI were performed to evaluate whether the anatomic characteristics of the cerebrum and cerebellum in a cohort of school-aged children (6-12 years of age) were related to gestational age at birth in children free of brain lesions in the perinatal period.

RESULTS: In the cohort consisting of 36 preterm (28-37 weeks' gestational age) and 66 term-born infants, T1-weighted MR imaging and DTI at $6-12$ years revealed a reduction of cerebellar white matter volume $(\beta=0.387, P<.001)$, altered fractional anisotropy of cerebellar white matter $(\beta=-0.236, P=.02)$, and a reduction of cerebellar gray and white matter surface area $(\beta=0.337, P<.001 ; \beta=0.375, P<.001$, respectively) in relation to birth age. Such relations were not observed for the cerebral cortex or white matter volume, surface area, or diffusion quantities.

CONCLUSIONS: The results of our study show that perinatal influences that are not primarily neurologic are still able to disturb long-term neurodevelopment, particularly of the developing cerebellum. Including the cerebellum in future neuroprotective strategies seems therefore essential.

ABBREVIATIONS: $F A=$ fractional anisotropy; $M D=$ mean diffusivity

$\mathbf{P}$ reterm birth and related complications are considered major risk factors for long-term functional impairment ${ }^{1-3}$ and have been associated with substantially increased health risks from birth to adulthood. ${ }^{4,5}$ Survival rates following preterm birth have substantially increased due to advances in perinatal care. How-

Received September 21, 2017; accepted after revision January 12, 2018.

From the Departments of Radiology and Medical Informatics (K.P., W.J.N.), Biomedical Imaging Group Rotterdam; Departments of Child and Adolescent Psychiatry (T.J.W.), Radiology (T.J.W.), Intensive Care and Paediatric Surgery (G.E.v.d.B., D.T.); Division of Neonatology, Department of Pediatrics (I.K.M.R.); and Department of Neuroscience (F.E.H.), Erasmus Medical Centre, Rotterdam, the Netherlands; Department of Imaging Physics (W.J.N.), Faculty of Applied Sciences, Delft University of Technology, Delft, the Netherlands; Quantib BV (W.J.N.), Rotterdam, the Netherlands; and Department of Perinatology (J.D.), Wilhelmina Children's Hospital and Brain Center Rudolf Magnus, University Medical Center Utrecht, Utrecht, the Netherlands.

The research of K.P. was funded by the Royal Dutch Medical Association, Erasmus Journal of Medicine grant. T.J.W. and F.E.H. are supported by ZON-MW TOP and Dutch Science Organization-VIDI grants.

Please address correspondence to Freek Hoebeek, MD, Erasmus Medical Center, Department of Neuroscience, Room Eel2-20A, Westzeedijk 353, 3015 AA, Rotterdam, the Netherlands; e-mail: f.hoebeek@erasmusmc.nl; or Jeroen Dudink, MD, Utrecht University Medical Centre, Department of Neonatology; Wilhelmina Children's Hospital, Lundlaan 6, 3584 EA, Utrecht, the Netherlands; e-mail:

j.dudink@umcutrecht.nl

ever, among survivors, neurocognitive and motor impairments are still frequent, ${ }^{6-8}$ despite a shift from large macroscopic white matter lesions toward subtler punctate lesions and microstructural abnormalities. ${ }^{9,10}$

Advanced imaging techniques have been widely adopted to study brain development and microstructure following preterm birth, with a predominant focus on studying cerebral structures. A limited number of studies assessing neurodevelopment following preterm birth have incorporated the cerebellum in imaging analysis. More attention toward cerebellar structures seems desirable now that recent evidence shows a potential role of the cerebellum in various nonmotor functions, including attention, cognition, and behavior ${ }^{1-14}$; disturbances of cerebellar development have been associated with a variety of nonmotor disorders, including autism spectrum disorder, ${ }^{15}$ schizophrenia, ${ }^{16}$ dyslexia, ${ }^{17}$ and attention deficit disorders. ${ }^{18}$

Disruptive influences on cerebellar microstructure and structures are likely to occur during perinatal stages, when growth and develop-

\footnotetext{
- Indicates open access to non-subscribers at www.ajnr.org

三 Indicates article with supplemental on-line tables.

http://dx.doi.org/10.3174/ajnr.A5589
} 
ment rates are highest and cerebellar microstructure is vulnerable. ${ }^{19,20}$ Imaging studies conducted thus far have suggested that cerebellar lesions within this period disturb cerebellar development and may secondarily impact cerebral development ${ }^{21,22}$; these findings suggest the existence of trophic interactions between the cerebellum and cerebrum during neurodevelopment and are in line with animal experiments showing the regulatory effects of the cerebellum on the development of supratentorial brain structures. ${ }^{23-25}$ Neonatal events that can disturb this complex interplay between cerebellar and cerebral development may be detrimental and may lead to functional impairment in later life.

To date, few neuroimaging studies have assessed the impact of preterm birth on the cerebellum and were, in great part, conducted during early perinatal stages, following major neurologic perinatal events (eg, hypoxic-ischemic encephalopathy, hemorrhages) and in infants born extremely preterm ( $<28$ weeks of gestation). Studies assessing the long-term impact of birth age on cerebellar structures are sparse, and only a few studies have attempted to quantify the long-term effects of preterm birth on cerebellar anatomy and microstructures. Whether preterm birth in children born after 28 weeks of gestation without brain injury on perinatal imaging influences cerebellar structures long-term remains to be elucidated.

In this study among preterm and term-born infants 6-12 years of age at the time of follow-up, we report neuroimaging data supporting the hypothesis that the cerebellum is particularly sensitive to even subtle perinatal disturbances.

\section{MATERIALS AND METHODS \\ Subjects}

MR imaging scans and neuropsychological assessment scores of 102 children scanned between 6 and 12 years of age were collected and analyzed. The included cohort was scanned as part of a prospective cohort study among children in Rotterdam and consisted of 36 preterm-born infants (28-37 weeks' gestational age) and 66 term-born controls (On-line Table 1). ${ }^{26}$ Exclusion criteria were the following: macroscopic brain injury seen on sonography during the hospital or neonatal intensive care stay of the infants born preterm (intraventricular hemorrhage, intraparenchymal lesions, stroke) and congenital abnormalities that could affect normal brain development negatively. Perinatal conditions of the infants and eventual adverse events are summarized in On-line Table 2.

All preterm infants had routine sonography assessment in the neonatal intensive care unit, which included scans at days 1,3 , and 7 after birth and once every other week during their neonatal intensive care unit stay. Ultrasounds were performed by expert neonatologists who had at least 2 years of experience with neonatal sonography. For cerebellar evaluation, the mastoid fontanelle was used as the acoustic window. Convex 5-10 MHz and linear 15-18 MHz probes (Esaote Diagnostic Imaging Systems, Genova, Italy) were used to assess the neonatal brain. Research ethics committee approval and written informed consent of parents and children were obtained before MR imaging.

\section{MR Imaging and Data Processing}

MR imaging at 6-12 years of age was performed between June 2011 and March 2013, using a 3T MR imaging system and consisted of T1-weighted MR imaging and DWI. T1-weighted imag- ing was performed using the following settings: $\mathrm{TR}=10.3 \mathrm{~ms}$, $\mathrm{TE}=4.2 \mathrm{~ms}$, TI $=350 \mathrm{~ms}$, matrix $=256 \times 256 \mathrm{~mm}$, isotropic resolution $=0.9 \times 0.9 \times 0.9 \mathrm{~mm}$, scan time $=5$ minutes 40 seconds. Diffusion-weighted imaging was performed using an echo-planar imaging sequence with the following settings: TR = $11,000 \mathrm{~ms}, \mathrm{TE}=83 \mathrm{~ms}$, flip angle $=90^{\circ}$, matrix $=128 \times 128$, $\mathrm{FOV}=256 \times 256 \mathrm{~mm}$, slice thickness $=2 \mathrm{~mm}$, number of slices $=$ 77 , acquisition time $=7$ minutes 40 seconds, 35 diffusion-weighted volumes $\left(b=1000 \mathrm{~s} / \mathrm{mm}^{2}\right), 3$ volumes without diffusion-weighting $\left(b=0 \mathrm{~s} / \mathrm{mm}^{2}\right)$, scan time $=7$ minutes 40 seconds. ${ }^{27}$ All scans were obtained without sedation of the patient on a 3T MR imaging system using cushions to minimize head motion.

Preprocessing consisted of visual inspection of raw diffusionweighted images and T1-weighted MR imaging in 3 orthogonal planes. Motion-corrupted images were excluded before analysis $(n=2)$. T1-weighted images were brain-extracted and registered to the diffusion-weighted images while correcting for EPI-induced deformities using the T1-weighted image as a reference. Diffusion-weighted data were corrected for motion-induced outliers, and tensors were calculated robustly using the REKINDLE (robust extraction of kurtosis indices with linear estimation) approach. ${ }^{28-31}$ Artifacts correction included correction for eddy currents, motion, and EPI-induced distortions. Preprocessing was performed using ExploreDTI, Version 4.8.5 (http:// exploredti.com/) running in Matlab (R2015; MathWorks, Natick, Massachusetts). ${ }^{29}$

Following preprocessing, we performed ROI analysis of cerebellar and cerebral regions based on automated white and gray matter segmentations (see On-line Tables 3 and 4 for more information on segmentation procedures and software). For each region, surface area and volume were calculated. Furthermore, probabilistic tractography of the following white matter tracts was performed using FSL (http://www.fmrib.ox.ac.uk/fsl) in conjunction with the AutoPtx plugin (https://fsl.fmrib.ox.ac.uk/fsl/ fslwiki/AutoPtx) for automated probabilistic tractography ${ }^{32,33}$ : cerebellar peduncles (superior, middle, and inferior), thalamic radiation (anterior, superior, and posterior), longitudinal fasciculus (superior and inferior), forceps (major and minor), and corticospinal tract. Fractional anisotropy (FA) and median diffusivity (MD) values were computed for each tract. For more information on toolboxes, ROI placement, and MR imaging atlases that were used, see On-line Tables 3 and 4. Segmentation of the cerebellum was performed using the spatially unbiased infratentorial and cerebellar template segmentation toolbox (SUIT; http://www.diedrichsenlab. org/imaging/propatlas.htm). Segmentation results in a representative subject are shown in Fig 1. ${ }^{34,35}$

\section{Statistical Analysis}

Statistical analysis was performed with SPSS Statistics for Windows, Version 22.0 (IBM, Armonk, New York). Linear regression analysis was performed to study the relationship between each structure that was delineated and gestational age, corrected for age at follow-up scanning and sex differences. The standardized regression coefficients and corresponding levels of significance are reported for each structure studied. Statistical results were corrected for multiple testing using a false discovery rate control procedure. $^{36}$

AJNR Am J Neuroradiol 39:956-62 May 2018 www.ajnr.org 957 


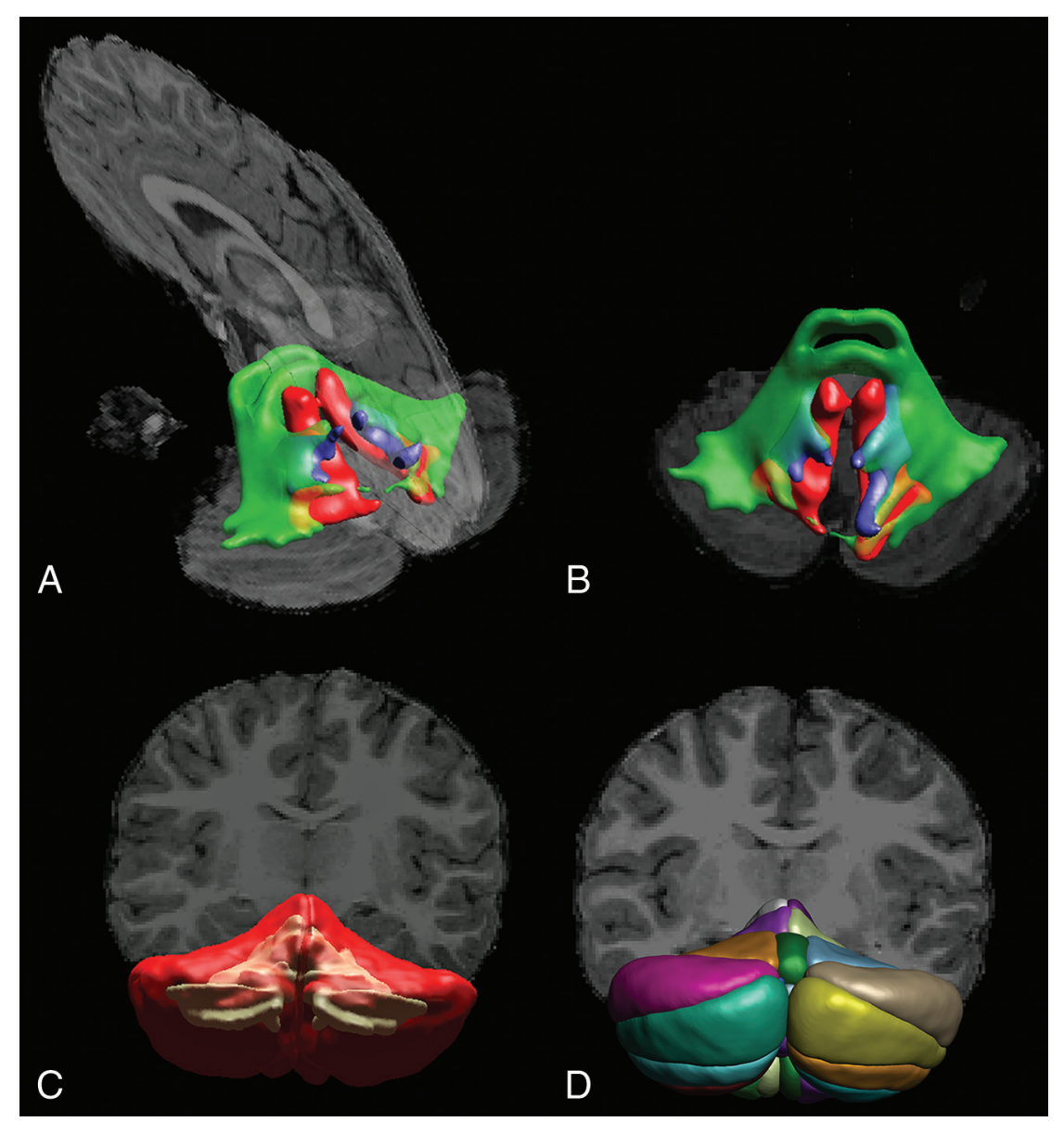

FIG 1. DTI-based tractography of the cerebellar peduncles $(A$ and $B)$ and T1-weighted image segmentation of white and gray matter $(C)$ and cerebellar lobules $(D)$ in a representative subject.

Table 1: Coefficients of the regression model for cerebral volumes and surface areas when accounting for age at scanning and sex differences as covariates

\begin{tabular}{lcccc}
\hline \multicolumn{1}{c}{ Dependent Variable } & $\begin{array}{c}\text { Standardized } \\
\text { Regression } \\
\text { Coefficient }(\boldsymbol{\beta})\end{array}$ & $\begin{array}{c}\text { Partial } \\
\text { Correlation } \\
\text { Coefficient }(\boldsymbol{r})\end{array}$ & $\begin{array}{c}\text { T Statistics } \\
\text { Significance } \\
\text { (2-Tailed) }\end{array}$ \\
\hline Total cerebral volume $\left(\mathrm{mm}^{3}\right)$ & 0.066 & 0.072 & 0.712 & .48 \\
Cerebral WM volume $\left(\mathrm{mm}^{3}\right)$ & 0.148 & 0.130 & 1.271 & .21 \\
Cerebral cortex GM volume $\left(\mathrm{mm}^{3}\right)$ & 0.058 & 0.054 & 0.526 & .60 \\
Cerebral WM surface area $\left(\mathrm{mm}^{2}\right)$ & 0.148 & 0.130 & 1.271 & .21 \\
Cerebral cortex surface area $\left(\mathrm{mm}^{2}\right)$ & 0.098 & 0.089 & 0.865 & .39 \\
\hline
\end{tabular}

a Predictors in the model that were held constant: age at follow-up MRI (years) and sex (M/F)

Table 2: Coefficients of the regression model for cerebellar volumes and surface areas when accounting for age at scanning and sex differences as covariates

\begin{tabular}{|c|c|c|c|c|}
\hline Dependent Variable $^{a}$ & $\begin{array}{l}\text { Standardized } \\
\text { Regression } \\
\text { Coefficient }(\boldsymbol{\beta})\end{array}$ & $\begin{array}{c}\text { Partial } \\
\text { Correlation } \\
\text { Coefficient }(r)\end{array}$ & & $\begin{array}{c}\text { Significance } \\
\text { (2-Tailed) }\end{array}$ \\
\hline Total cerebellar volume $\left(\mathrm{mm}^{3}\right)$ & 0.224 & 0.195 & 1.945 & .06 \\
\hline Cerebellar WM volume $\left(\mathrm{mm}^{3}\right)$ & 0.387 & 0.357 & 3.703 & $<.001^{\mathrm{b}}$ \\
\hline Cerebellar GM volume $\left(\mathrm{mm}^{3}\right)$ & 0.134 & 0.118 & 1.150 & .25 \\
\hline Cerebellar WM surface area $\left(\mathrm{mm}^{2}\right)$ & 0.387 & 0.357 & 3.703 & $<.001^{\mathrm{b}}$ \\
\hline Cerebellar cortex surface area $\left(\mathrm{mm}^{2}\right)$ & 0.375 & 0.350 & 3.621 & $<.001^{\mathrm{b}}$ \\
\hline
\end{tabular}

${ }^{a}$ Predictors in the model that were held constant: age at follow-up MRI (years) and sex (M/F).

${ }^{\mathrm{b}}$ Significant.

\section{RESULTS}

\section{Volumetric Analysis}

Regression analysis of cerebellar and cerebral structures revealed significant alterations of cerebellar white and gray matter struc- tures in relation to birth age, but not of analogous cerebral components (Tables 1 and 2). While we corrected for age at MR imaging and sex differences, lower gestational age at birth was associated with lower total cerebellar volume (standardized regression coefficient, $\beta=$ $0.191, P=.04)$, whereas this was not found for the cerebral volume $(\beta=$ $0.057, P=.54)$. When we evaluated gray and white matter separately, this relation was consistently observed; cerebellar white matter volume $(\beta=0.336, P<$ $.001)$ and surface area $(\beta=0.346, P<$ $.001)$ were significantly reduced in relation to lower gestational age at birth (Fig $2 E,-G)$, while for cerebral white matter volume $(\beta=0.098, P=.27)$ and surface area $(\beta=0.127, P=.17)$, no significant relationship was observed (Fig $2 A,-C$ ). When comparing cerebellar and cerebral gray matter, we again found a significant negative correlation between the cerebellar gray matter surface area and gestational age at birth $(\beta=0.337$, $P<.001$ ) (Fig $2 H$ ), while cerebral cortex surface area was not significantly correlated with gestational age at birth $(\beta=$ $0.073, P=.43$ ) (Fig $2 D)$. Further subdivision of the cerebellar cortex in anatomic lobules according to the Schmahmann et al (1999) ${ }^{37}$ atlas definitions did not highlight specific parts of the cerebellar cortex as being more predominantly affected in relation to gestational age than others (On-line Table 5).

After false discovery rate correction, which was performed to minimize the risk of false-positive significant findings, the volume and surface areas of cerebellar white matter $(\beta=0.336, P<.001)$ as well as cerebellar gray matter surface area $(\beta=0.337, P<.001)$ were consistently identified as being significantly associated with gestational age at birth.

\section{DTI Analysis and Tractography}

When we looked at diffusion properties of cerebral white matter, cerebral white matter FA and MD were not significantly associated with gestational age $(\beta=-0.016, P=.88$ and $\beta=-0.119$, $P=.22$ ), while for cerebellar white matter, a significant association was observed between cerebellar white matter fractional anisotropy and gestational age at birth $(\beta=-0.266, P=.008)$. When we looked at gray matter, neither cerebral nor cerebellar FA and MD were 

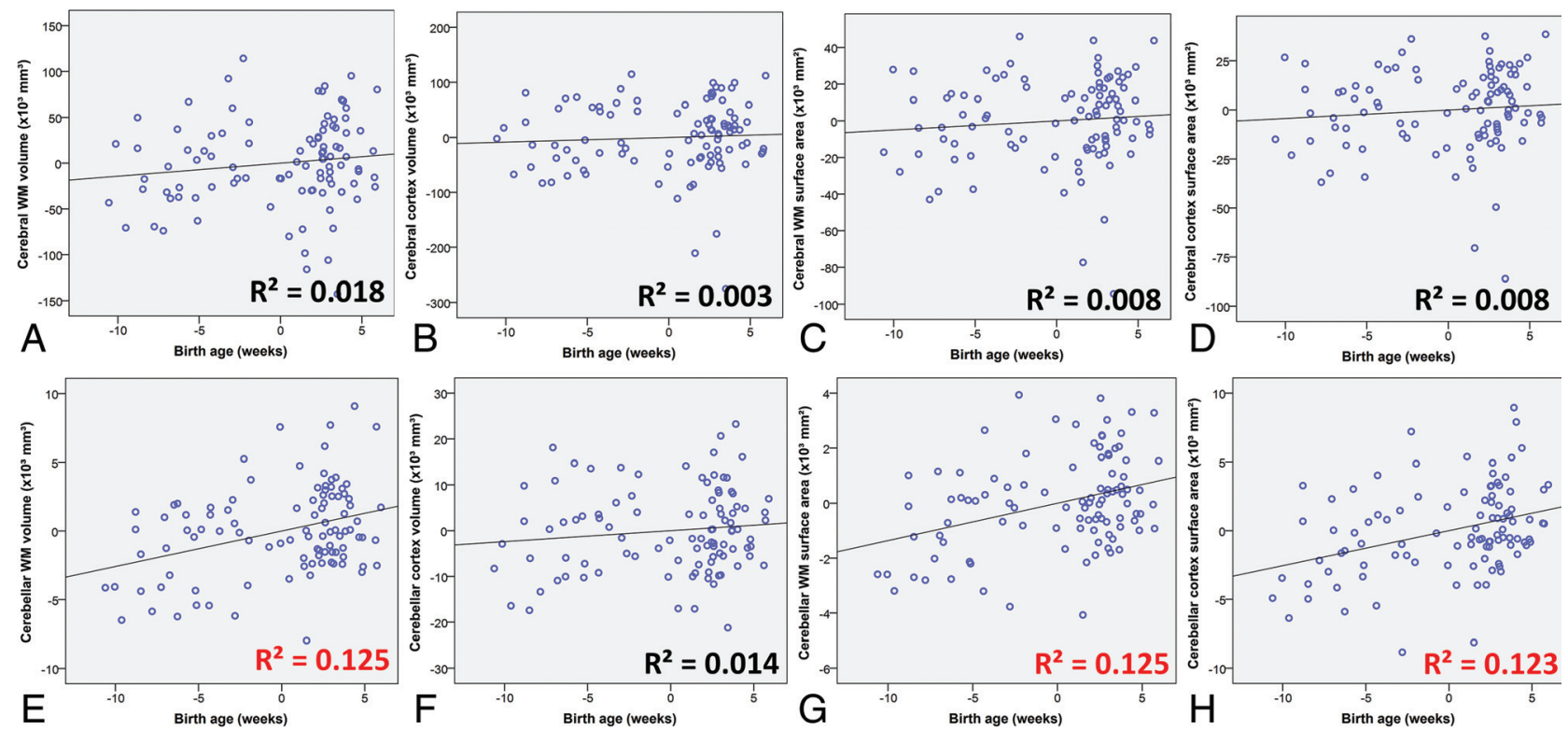

FIG 2. Linear regression analysis plots of cerebral and cerebellar structures in infancy in relation to birth age. Sex and age at follow-up MR imaging were included in the partial regression model as covariates. Significant $R^{2}$ correlation coefficients are highlighted in red. The horizontal axis indicates age at birth in weeks relative to term-equivalent age (37 weeks).

Table 3: Coefficient of the regression model for diffusion MRI measurements of the cerebellum and cerebrum corrected for age at scanning and sex differences

\begin{tabular}{|c|c|c|c|c|}
\hline Dependent Variable $^{a}$ & $\begin{array}{l}\text { Standardized } \\
\text { Regression } \\
\text { Coefficient }(\boldsymbol{\beta})\end{array}$ & $\begin{array}{c}\text { Partial } \\
\text { Correlation } \\
\text { Coefficient }(r)\end{array}$ & $T$ Statistics & $\begin{array}{c}\text { Significance } \\
\text { (2-Tailed) }\end{array}$ \\
\hline Cerebellar white matter FA & -0.236 & -0.238 & -2.379 & $.02^{\mathrm{b}}$ \\
\hline Cerebellar white matter MD & -0.049 & -0.049 & -0.476 & .64 \\
\hline Cerebellar gray matter FA & -0.104 & -0.102 & -0.992 & .32 \\
\hline Cerebellar gray matter MD & -0.098 & -0.095 & -0.922 & .36 \\
\hline Cerebral white matter FA & 0.008 & 0.008 & 0.078 & .94 \\
\hline Cerebral white matter MD & -0.109 & -0.104 & -1.014 & .31 \\
\hline Cerebral cortex FA & -0.129 & -0.123 & -1.205 & .23 \\
\hline Cerebral cortex MD & -0.059 & -0.058 & -0.568 & .57 \\
\hline
\end{tabular}

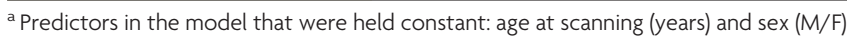

bignificant.

significantly associated with gestational age at birth (Table 3). Tractography results of neither cerebellar nor cerebral tracts revealed obvious trends in diffusion characteristics in relation to gestational age at birth (On-line Table 6).

\section{DISCUSSION}

In this study, we have performed a structural assessment to evaluate cerebral and cerebellar structures in a cohort of preterm and term-born infants at school age who were free of intracranial lesions in the perinatal period. Our results show profound, longterm trophic effects on cerebellar structures related to birth age in infants free of neurologic complications in the perinatal period. In previous research, perinatal stages were shown to be essential for cerebellar morphogenesis, growth, and development, in that cerebellar aberrations were commonly described in infants with noncerebellar neurologic pathologies (eg, hemorrhages, stroke) or major perinatal events such as profound hypoxia. ${ }^{20,21}$ Studies evaluating the consequences of prematurity on the cerebellum and cerebrum in the absence of perinatal brain lesions were mostly conducted during the early postnatal stages and were therefore unable to differentiate between delayed maturation and persistent cerebellar changes. ${ }^{1}$

In our cohort, trophic effects related to birth age were most pronounced in cerebellar white matter volume and cerebellar cortex surface area, as well as in cerebellar white matter microstructures as measured by DTI. These results suggest that particularly the cerebellum is sensitive to perinatal disturbances and that even in the absence of neurovascular events, long-term brain development is affected by perinatal circumstances related to prematurity. Possible mechanisms underlying impaired development are suboptimal oxygen levels due to lung immaturity, inflammation due to infections, and impaired regulation of essential nutrients. ${ }^{38-42}$

The negative impact on cerebellar development that was observed in this study is of particular relevance for child health because disrupted cerebellar development has been associated with a variety of debilitating disorders, including autism spectrum disorder, ${ }^{15}$ schizophrenia, ${ }^{16}$ dyslexia, ${ }^{17}$ and attention deficit disorders. ${ }^{18}$ The provided evidence for developmental disturbances of the cerebellum in the absence of neurovascular events demands larger cohort studies with sufficient power to characterize underlying injury mechanisms. Due to advances in neonatal care, the most commonly seen brain injuries in current clinical practice are shifting from large intracranial lesions toward more subtle disturbances. Therefore, a better understanding of more subtle injury mechanisms would allow further improvement in neonatal care and would help in targeting future neuroprotective strategies toward anatomic regions that are considered most vulnerable. The apparent sensitivity of the cerebellum to perinatal influences that was found in this study is consistent with scientific litera- 
ture $\mathrm{e}^{15,19,20,43}$ and indicates that a dedicated focus on the cerebellum is desirable in future research toward new neuroprotective strategies.

No significant relations were observed between tract profiles of white matter pathways and age at birth in our cohort. A limited number of diffusion-encoding directions in the applied imaging protocol restricted the ability of tracking through crossing-fiber regions in the brain. Future studies using more advanced tractography methods may allow a more detailed characterization of white matter tracts connecting cerebellar hemispheres to contralateral cerebral cortices. In the literature, it has been hypothesized that during the early stages of development, impairment in cerebellar structures might affect cerebral development and vice versa. ${ }^{21,43,44}$ It is therefore possible that alterations in supratentorial brain regions that have been reported in many studies of infants born preterm to some extent relate to impaired cerebellar development and related impaired trophic interactions. ${ }^{21,45}$ Advanced neuroimaging or axonal tracing experiments in human postmortem tissue may provide more insight about cerebellocerebral connectivity. ${ }^{46-48}$

For cerebellar white matter, we found a significant increase in white matter FA in infants born earlier, while tractography results of cerebellar tracts were not related to gestational age at birth. The latter finding is remarkable given that our data also showed clear associations between gestational age at birth and cerebellar white matter volume and gray matter surface area. It may be that an increase in FA of total cerebellar white matter in infants born earlier reflects higher fiber coherence and myelination or that the increase in FA results from a decreased complexity of fiber orientations. In the latter case, the extent of fanning and/or crossing fibers is lower in children born earlier, which in turn results in higher FA when using a diffusion tensor model that is inherently unable to adequately represent complex fiber configurations. ${ }^{49-51}$ Future studies using recently developed advanced imaging techniques that can capture more complex fiber orientations are needed to clarify this issue. ${ }^{46-48}$

Persistent abnormalities in cerebellar volume and surface area that were observed in this study are likely a result of irreversible cellular changes during perinatal stages, when cerebellar proliferation and differentiation rates are highest. In the period between 24 and 40 weeks of gestation, cerebellar volume and surface area increase exponentially due to highly active proliferative zones and rapid migration and differentiation of precursor cells. Preterm birth occurs within this critical timeframe and is likely able to disturb these delicate processes, even in the absence of observable cerebellar lesions. Although infants with intraparenchymal lesions on perinatal sonography were excluded from analysis, we acknowledge that it is unknown whether subtler cerebellar lesions and punctate cerebellar hemorrhages ( $<4 \mathrm{~mm}$ diameter) that are quickly resolved are overlooked in current neuroimaging approaches due to limited spatial resolution of both MR imaging and sonography. ${ }^{52-55}$

Future studies using more advanced imaging approaches that would allow a more detailed assessment of cerebellocerebral connectivity and interaction are needed to elucidate whether changes in cerebellar microstructures and structures result in impaired cerebellocerebral connectivity.

\section{CONCLUSIONS}

We have demonstrated the long-term effects of neurologically uncomplicated preterm birth at $\geq 28$ weeks' gestational age on cerebellar structures and microstructure. The results of our study suggest a particular vulnerability of the cerebellum to adverse effects of preterm birth, even in the absence of neurologic complications. A special focus on the cerebellum seems therefore essential in fundamental research toward the development of future neuroprotective strategies and predictive models of outcome.

\section{ACKNOWLEDGMENTS}

We thank the participants of the study.

Disclosures: Kay Pieterman—RELATED: Grant: Royal Dutch Medical Association, Erasmus Journal of Medicine grant, Comments: research grant of $€ 5000$ offered by the university to honors class students. ${ }^{*}$ Tonya J. White-RELATED: Grant: Netherlands Organization for Health Research and Development, Comments: TOP project number 91211021*. Wiro J. Niessen—UNRELATED: Consultancy: Quantib BV, Comments: scientific advisor*; Stock/Stock Options: Quantib BV, Comments: cofounder and stockholder. Freek E. Hoebeek—UNRELATED: Grants/Grants Pending: Dutch Science Organization, Comments: individual fellowship (VIDI-scheme). * $M o n e y$ paid to the institution.

\section{REFERENCES}

1. de Kieviet JF, Zoetebier L, van Elburg RM, et al. Brain development of very preterm and very low-birthweight children in childhood and adolescence: a meta-analysis. Dev Med Child Neurol 2012;54: 313-23 CrossRef Medline

2. Bos AF, Van Braeckel KN, Hitzert MM, et al. Development of fine motor skills in preterm infants. Dev Med Child Neurol 2013; 55(Suppl 4):1-4 CrossRef Medline

3. Svedenkrans J, Henckel E, Kowalski J, et al. Long-term impact of preterm birth on exercise capacity in healthy young men: a national population-based cohort study. PLoS One 2013;8:e80869 CrossRef Medline

4. Abitbol CL, Rodriguez MM. The long-term renal and cardiovascular consequences of prematurity. Nat Rev Nephrol 2012;8:265-74 CrossRef Medline

5. Ali K, Greenough A. Long-term respiratory outcome of babies born prematurely. Ther Adv Respir Dis 2012;6:115-20 CrossRef Medline

6. Grisaru-Granovsky S, Reichman B, Lerner-Geva L, et al. Populationbased trends in mortality and neonatal morbidities among singleton, very preterm, very low birth weight infants over 16 years. Early Hum Dev 2014;90:821-27 CrossRef Medline

7. Marlow N, Wolke D, Bracewell MA, et al. Neurologic and developmental disability at six years of age after extremely preterm birth. N Engl J Med 2005;352:9-19 CrossRef Medline

8. Platt MJ, Cans C, Johnson A, et al. Trends in cerebral palsy among infants of very low birthweight $(<1500 \mathrm{~g})$ or born prematurely (<32 weeks) in 16 European centres: a database study. Lancet 2007; 369:43-50 CrossRef Medline

9. Hamrick SE, Miller SP, Leonard C, et al. Trends in severe brain injury and neurodevelopmental outcome in premature newborn infants: the role of cystic periventricular leukomalacia. J Pediatr 2004;145:593-99 CrossRef Medline

10. Ferriero DM. Neonatal brain injury. N Engl J Med 2004;351:1985-95 CrossRef Medline

11. Brossard-Racine M, du Plessis AJ, Limperopoulos C. Developmental cerebellar cognitive affective syndrome in ex-preterm survivors following cerebellar injury. Cerebellum 2015;14:151-64 CrossRef Medline

12. E KH, Chen SH, Ho MH, et al. A meta-analysis of cerebellar contributions to higher cognition from PET and fMRI studies. Hum Brain Mapp 2014;35:593-615 CrossRef Medline

13. Koziol LF, Budding D, Andreasen N, et al. Consensus paper: the 
cerebellum's role in movement and cognition. Cerebellum 2014;13: 151-77 CrossRef Medline

14. Mazzola V, Vuilleumier $P$, Latorre V, et al. Effects of emotional contexts on cerebello-thalamo-cortical activity during action observation. PLoS One 2013;8:e75912 CrossRef Medline

15. Wang SS, Kloth AD, Badura A. The cerebellum, sensitive periods, and autism. Neuron 2014;83:518-32 CrossRef Medline

16. Wagner G, De la Cruz F, Schachtzabel C, et al. Structural and functional dysconnectivity of the fronto-thalamic system in schizophrenia: a DCM-DTI study. Cortex 2015;66:35-45 CrossRef Medline

17. Eckert MA, Leonard CM, Richards TL, et al. Anatomical correlates of dyslexia: frontal and cerebellar findings. Brain 2003;126:482-94 CrossRef Medline

18. Berquin PC, Giedd JN, Jacobsen LK, et al. Cerebellum in attentiondeficit hyperactivity disorder: a morphometric MRI study. Neurology 1998;50:1087-93 CrossRef Medline

19. Volpe JJ. Cerebellum of the premature infant: rapidly developing, vulnerable, clinically important. J Child Neurol 2009;24:1085-104 CrossRef Medline

20. Limperopoulos C, Soul JS, Gauvreau K, et al. Late gestation cerebellar growth is rapid and impeded by premature birth. Pediatrics 2005 ; 115:688-95 CrossRef Medline

21. Limperopoulos C, Soul JS, Haidar H, et al. Impaired trophic interactions between the cerebellum and the cerebrum among preterm infants. Pediatrics 2005;116:844-50 CrossRef Medline

22. Limperopoulos C, Chilingaryan G, Sullivan N, et al. Injury to the premature cerebellum: outcome is related to remote cortical development. Cereb Cortex 2014;24:728-36 CrossRef Medline

23. Martin GF, Cabana T, Hazlett JC, et al. Development of brainstem and cerebellar projections to the diencephalon with notes on thalamocortical projections: studies in the North American opossum. J Comp Neurol 1987;260:186-200 CrossRef Medline

24. Lotto RB, Price DJ. The stimulation of thalamic neurite outgrowth by cortex-derived growth factors in vitro: the influence of cortical age and activity. Eur J Neurosci 1995;7:318-28 CrossRef Medline

25. Hisanaga K, Sharp FR. Marked neurotrophic effects of diffusible substances released from non-target cerebellar cells on thalamic neurons in culture. Brain Res Dev Brain Res 1990;54:151-60 CrossRef Medline

26. van den Bosch GE, White T, El Marroun H, et al. Prematurity, opioid exposure and neonatal pain: do they affect the developing brain? Neonatology 2015;108:8-15 CrossRef Medline

27. White T, El Marroun H, Nijs I, et al. Pediatric population-based neuroimaging and the Generation R Study: the intersection of developmental neuroscience and epidemiology. Eur J Epidemiol 2013; 28:99-111 CrossRef Medline

28. Irfanoglu MO, Walker L, Sarlls J, et al. Effects of image distortions originating from susceptibility variations and concomitant fields on diffusion MRI tractography results. Neuroimage 2012;61:275-88 CrossRef Medline

29. Leemans A, Jeurissen B, Sijbers J, et al. ExploreDTI: a graphical toolbox for processing, analyzing, and visualizing diffusion MR data. In: Proceedings of the 17th Annual Meeting of International Society for Magnetic Resonance in Medicine, Honolulu, Hawaii. April 18-24, 2009;209:3537

30. Leemans A, Jones DK. The B-matrix must be rotated when correcting for subject motion in DTI data. Magn Reson Med 2009;61: 1336-49 CrossRef Medline

31. Tax CM, Otte WM, Viergever MA, et al. REKINDLE: robust extraction of kurtosis indices with linear estimation. Magn Reson Med 2015;73:794-808 CrossRef Medline

32. Jenkinson M, Beckmann CF, Behrens TE, et al. FSL. Neuroimage 2012;62:782-90 CrossRef Medline

33. de Groot M, Vernooij MW, Klein S, et al. Improving alignment in tract-based spatial statistics: evaluation and optimization of image registration. Neuroimage 2013;76:400-11 CrossRef Medline

34. Diedrichsen J, Balsters JH, Flavell J, et al. A probabilistic MR atlas of the human cerebellum. Neuroimage 2009;46:39-46 CrossRef Medline

35. Diedrichsen J. A spatially unbiased atlas template of the human cerebellum. Neuroimage 2006;33:127-38 CrossRef Medline

36. Benjamini Y, Hochberg Y. Controlling the false discovery rate: a practical and powerful approach to multiple testing. Journal of the Royal Statistical Society Series B (Methodological) 1995;57:289-300

37. Schmahmann JD, Doyon J, McDonald D, et al. Three-dimensional MRI atlas of the human cerebellum in proportional stereotaxic space. Neuroimage 1999;10:233-60 CrossRef Medline

38. Baraldi E, Filippone M. Chronic lung disease after premature birth. N Engl J Med 2007;357:1946-55 CrossRef Medline

39. Keunen K, van Elburg RM, van Bel F, et al. Impact of nutrition on brain development and its neuroprotective implications following preterm birth. Pediatr Res 2015;77:148-55 CrossRef Medline

40. Beardsall K, Dunger D. The physiology and clinical management of glucose metabolism in the newborn. Endocr Dev 2007;12:124-37 Medline

41. Schmid MB, Hopfner RJ, Lenhof S, et al. Cerebral oxygenation during intermittent hypoxemia and bradycardia in preterm infants. Neonatology 2015;107:137-46 CrossRef Medline

42. Rizzo T, Metzger BE, Burns WJ, et al. Correlations between antepartum maternal metabolism and intelligence of offspring. $N$ Engl J Med 1991;325:911-16 CrossRef Medline

43. Limperopoulos C, Chilingaryan G, Guizard N, et al. Cerebellar injury in the premature infant is associated with impaired growth of specific cerebral regions. Pediatr Res 2010;68:145-50 CrossRef Medline

44. Bolduc ME, Du Plessis AJ, Evans A, et al. Cerebellar malformations alter regional cerebral development. Dev Med Child Neurol 2011;53: 1128-34 CrossRef Medline

45. Ball G, Boardman JP, Rueckert D, et al. The effect of preterm birth on thalamic and cortical development. Cereb Cortex 2012;22:1016-24 CrossRef Medline

46. Pieterman K, Batalle D, Dudink J, et al. Cerebello-cerebral connectivity in the developing brain. Brain Struct Funct 2017;222:1625-34 CrossRef Medline

47. Palesi F, Tournier JD, Calamante F, et al. Contralateral cerebellothalamo-cortical pathways with prominent involvement of associative areas in humans in vivo. Brain Struct Funct 2015;220: 3369-84 CrossRef Medline

48. Palesi F, Tournier JD, Calamante F, et al. Reconstructing contralateral fiber tracts: methodological aspects of cerebello-thalamocortical pathway reconstruction. Funct Neurol 2016;31:229-38 Medline

49. Descoteaux M, Deriche R, Knösche TR, et al. Deterministic and probabilistic tractography based on complex fibre orientation distributions. IEEE Trans Med Imaging 2009;28:269-86 CrossRef Medline

50. Kristo G, Leemans A, Raemaekers M, et al. Reliability of two clinically relevant fiber pathways reconstructed with constrained spherical deconvolution. Magn Reson Med 2013;70:1544-56 CrossRef Medline

51. Tournier JD, Yeh CH, Calamante F, et al. Resolving crossing fibres using constrained spherical deconvolution: validation using diffusion-weighted imaging phantom data. Neuroimage 2008;42:617-25 CrossRef Medline

52. Plaisier A, Raets MM, Ecury-Goossen GM, et al. Serial cranial ultrasonography or early MRI for detecting preterm brain injury? Arch Dis Child Fetal Neonatal Ed 2015;100:F293-300 CrossRef Medline

53. Plaisier A, Govaert $\mathrm{P}$, Lequin $\mathrm{MH}$, et al. Optimal timing of cerebral MRI in preterm infants to predict long-term neurodevelopmental outcome: a systematic review. AJNR Am J Neuroradiol 2014;35: 841-47 CrossRef Medline

54. Heemskerk AM, Leemans A, Plaisier A, et al. Acquisition guidelines and quality assessment tools for analyzing neonatal diffusion tensor MRI data. AJNR Am J Neuroradiol 2013;34:1496-505 CrossRef Medline 
55. Ecury-Goossen GM, Camfferman FA, Leijser LM, et al. State of the art cranial ultrasound imaging in neonates. J Vis Exp 2015:e52238 CrossRef Medline

56. Destrieux C, Fischl B, Dale A, et al. Automatic parcellation of human cortical gyri and sulci using standard anatomical nomenclature. Neuroimage 2010;53:1-15 CrossRef Medline
57. Behrens TE, Woolrich MW, Jenkinson M, et al. Characterization and propagation of uncertainty in diffusion-weighted MR imaging. Magn Reson Med 2003;50:1077-88 CrossRef Medline

58. Behrens TE, Berg HJ, Jbabdi S, et al. Probabilistic diffusion tractography with multiple fiber orientations: what can we gain? Neuroimage 2007;34:144-55 CrossRef Medline 